\title{
Isotherm adsorption characteristics of carbon microparticles prepared from pineapple peel waste
}

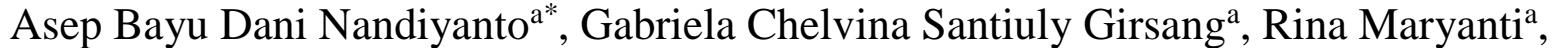 \\ Risti Ragadhita ${ }^{a}$, Sri Anggraeni ${ }^{a}$, Fajar Miraz Fauzi ${ }^{a}$, Putri Sakinah ${ }^{a}$, Asita Puji Astutia, \\ Dian Usdiyana $^{a}$, Meli Fiandini ${ }^{a}$, Mauseni Wantika Dewi ${ }^{a}$, Abdulkareem Sh. Mahdi Al-Obaidi ${ }^{b}$ \\ ${ }^{a}$ Universitas Pendidikan Indonesia, Bandung 40154, Indonesia \\ ${ }^{b}$ School of Computer Science and Engineering, Faculty of Innovation and Technology, Taylor's University, Selangor DE, Malaysia
}

Article history:

Received: 11 May 2020 / Received in revised form: 30 May 2020 / Accepted: 1 June 2020

\begin{abstract}
The objective of this study was to investigate the isotherm adsorption of carbon microparticles from pineapple peel waste. The carbon microparticles were prepared by carbonizing pineapple peel waste at the temperature of $215-250^{\circ} \mathrm{C}$ and grinding using a saw-milling process. To investigate the adsorption properties of carbon microparticles, we conducted some experiments by evaluating adsorption using curcumin (as a model of adsorbate) at the ambient temperature and pressure under a constant $\mathrm{pH}$ condition. To confirm the adsorption characteristics,

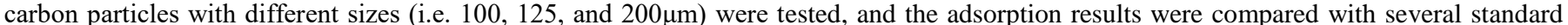
isotherm adsorption models: Langmuir, Freundlich, Temkin, and Dubinin-Radushkevich. To support the adsorption analysis, several characterizations (i.e. optical microscope and Fourier transform infrared analysis) were conducted. The adsorption test showed that the adsorption profiles of carbon microparticles for all particle sizes were fit to the Freundlich model, indicating the multilayer adsorption process on heterogeneous surfaces. The results from other isotherm models also confirmed that the adsorption process occurred physically via Van der Waals force in binding adsorbate on the surface of adsorbent. The existence of multilayer without cooperative adsorption between adsorbate molecules confirmed the impact of surface structure (i.e. pores) in the adsorbent on the adsorption process. This study demonstrated phenomena occurred during the adsorption process, which can be used for further applications, in particular when using carbon from organic waste as a catalyst and an adsorbent.
\end{abstract}

Keywords: Adsorption Isotherm, carbon; distribution particles, pineapple peel

\section{Introduction}

Carbon is one of the fourth most abundant elements in universe [1]. It is easily integrated with various elements to create thousands of organic compounds, composites, and minerals. Carbon is found in all organisms, and involves in the decaying process and molecular transformation of living organism. More than $90 \%$ of carbon is also found as the synthetic compounds [2], and $10 \%$ is obtained in living organisms, such as plants, animals, fungi, microorganisms, and fossils [3].

Carbon has been found in several applications, such as gas absorbent agents, reducing agents in many metallurgical processes, and chemical reagents in the process of making sodium salicylate, potassium, ammonium carbonate, and bicarbonate [4].

One of the carbon sources is fruit waste since for having the high content of carbon element. Many papers [5-10] have reported a number of strategies for producing carbon from these types of wastes: mango peel [5], lemon peel [6],

\footnotetext{
* Corresponding author.
}

Email: nandiyanto@upi.edu dragon fruit peel [7], jackfruit peel [8], rice straw [9], and rice husk [10]. The use of this waste type is important since it can give benefits in increasing product's added value (i.e. transforming useless waste into the high selling carbon products). Indeed, this can encourage efforts to generate economy, creating jobs and useful especially for developing countries [11].

Although there are many reports on the synthesis and characterizations of carbon material, studies on the adsorption properties of carbon from organic waste so far have not been reported in detail, especially in the use of fruit waste. In fact, this information is crucial for understanding what phenomena occur during the adsorption process in which they can be used for further uses, especially when using carbon as a catalyst and an adsorbent.

In our previous studies [12,13], we reported the evaluation of isotherm adsorption of silica [12] and carbon [13] particles from agricultural waste (i.e. rice husk). Here, the purpose of this study was to evaluate the isotherm adsorption of carbon microparticles from pineapple peel waste. 
Different from other studies focused on the synthesis and characterization of carbon only, the main novelty in this study was to analyze the isotherm adsorption of carbon particles from pineapple peel waste. Such waste was the main focus as the carbon source for having the high amount of carbon components such as cellulose, lignin, and hemicellulose [14], making them promising as the carbon source. Pineapple is also one of the most product commodities in tropical countries. For example, in Europe, the majority of pineapples in market come from Costa Rica as the tropical countries, supplying $75 \%$ of the pineapples found in the EU [15].

Other novelty was the evaluation of isotherm adsorption of carbon particles with various particle sizes in the micrometer range. Carbon particles with different sizes (i.e. 100,125 , and $200 \mu \mathrm{m}$ ) were tested, and the adsorption results were compared with several standard isotherm adsorption models: Langmuir, Freundlich, Temkin, and Dubinin-Radushkevich models. In general, particle size relates to the surface active sites (the main place for the adsorption process). Increases in the particle size have a direct correlation with the increase of the number of adsorption sites, altering the adsorption profile of adsorbent. By understanding adsorption profile as a function of particle size, it can be concluded what adsorption phenomena occur in the carbon particles.

Different from other reports, our experiments were facile, evaluating adsorption using curcumin (as a model of adsorbate) at the ambient temperature and pressure under constant $\mathrm{pH}$ condition. Curcumin was selected as a model of organic adsorbate molecule considering that it had an ideal molecular size (less than $1.4 \mathrm{~nm}$ ) [16-18], perfect for evaluating adsorbent-adsorbate interaction and making it possible for predicting other types of adsorptives.

In addition, while other studies typically focused on the performance of nanoparticles, this study emphasized the analysis of carbon particles with sizes in the micrometer range. Micrometer-sized particles are interested to be evaluated since they have some excellent characteristics compared to nanoparticles, bulk, and film materials. Microparticles are unique because they are easily settled and decanted spontaneously - different from nanoparticles requiring some specific treatments for the separation process. This makes carbon microparticles are separated easily after being used, allowing them to be reusable. Further, their settling ability promotes them for not contaminating the sample for analysis, avoiding misleading measurement as well as giving precise evaluation and analysis.

\section{Isotherm Adsorption Models used in This Study}

This study used four types of isotherm adsorption models: Freundlich, Langmuir, Temkin, and DubininRadushkevich models. The isotherm models predicted the phenomena during the adsorption process, based on the concentration of adsorbate and the amount of solution adsorbed per mass of the adsorbent at equilibrium [19].

Fig. 1 illustrates the adsorption profile in which Fig. 1(a) and Fig. 1(b) are for the multilayer and monolayer adsorption models, respectively. The figures also describe the possible standard isotherm adsorption models. Detailed information about the models are described as follows.

The Freundlich isotherm adsorption model discusses about the type of adsorption on heterogeneous surfaces with interactions between adsorbed molecules. Multilayer adsorption can be applied in this isotherm model [18]. This model implies that the adsorption energy decreases along with the adsorption process in the adsorbent, in which it can be written as:

$$
\log Q_{e}=\log k_{f}+\frac{1}{n} \log C_{e}
$$

where $k_{f}$ is the Freundlich constant (an approximate indicator of adsorption capacity) and $C_{e}$ is the concentration of adsorbate under equilibrium conditions $(\mathrm{mg} / \mathrm{L}) . \quad n$ is the non-linear degree, describing the type of adsorption process [20]:

(i) $n<1$ replies an adsorption with chemical process.

(ii) $n=1$ implies a linier adsorption (the partition between the two phases that are independent in the concentrations).

(iii) $n>1$ defines an adsorption with a physical process.

The definition of $n$ can be re-derived using $1 / n$ (a function of the strength of adsorption in the adsorption process), which is described as [21]:

(i) $1 / n<1$ replies a normal adsorption.

(ii) $1 / n>1$ implies cooperative adsorption where adsorbed adsorbate affects and influences the adsorption of free adsorbates.

(iii) $1<1 / n<0$ informs the favorable sorption process, discouraging desorption process.

(iv) $0<1 / n<1$ defines a measurement of adsorption intensity or surface heterogeneity. When the value gets closer to 0 , the surface will be more heterogeneous.

The Langmuir isotherm model assumes monolayer adsorption on homogeneous surfaces. Adsorption occurs without any interaction with adsorbed molecules and has a similar energy on the surface (without any transmigration from adsorbate) [22]. The formation of a monolayer adsorbate on the outer surface of the adsorbent obstructs further adsorption [23]. The correlations used for predicting Langmuir model are [24]:

$$
\frac{1}{Q_{e}}=\frac{1}{Q_{\max } K_{L}} \frac{1}{C_{e}}+\frac{1}{Q_{\max }}
$$

$$
R_{L}=\frac{1}{1+K_{L} C_{e}}
$$

where $K_{L}$ and $Q_{\max }$ are the Langmuir adsorption constant and the monolayer adsorption capacity (mg/g), respectively. $R_{L}$ value is the separation factor, used for classifying the adsorption process [25]:

(i) $R_{L}>1$ is an unfavorable adsorption, encouraging a desorption; 


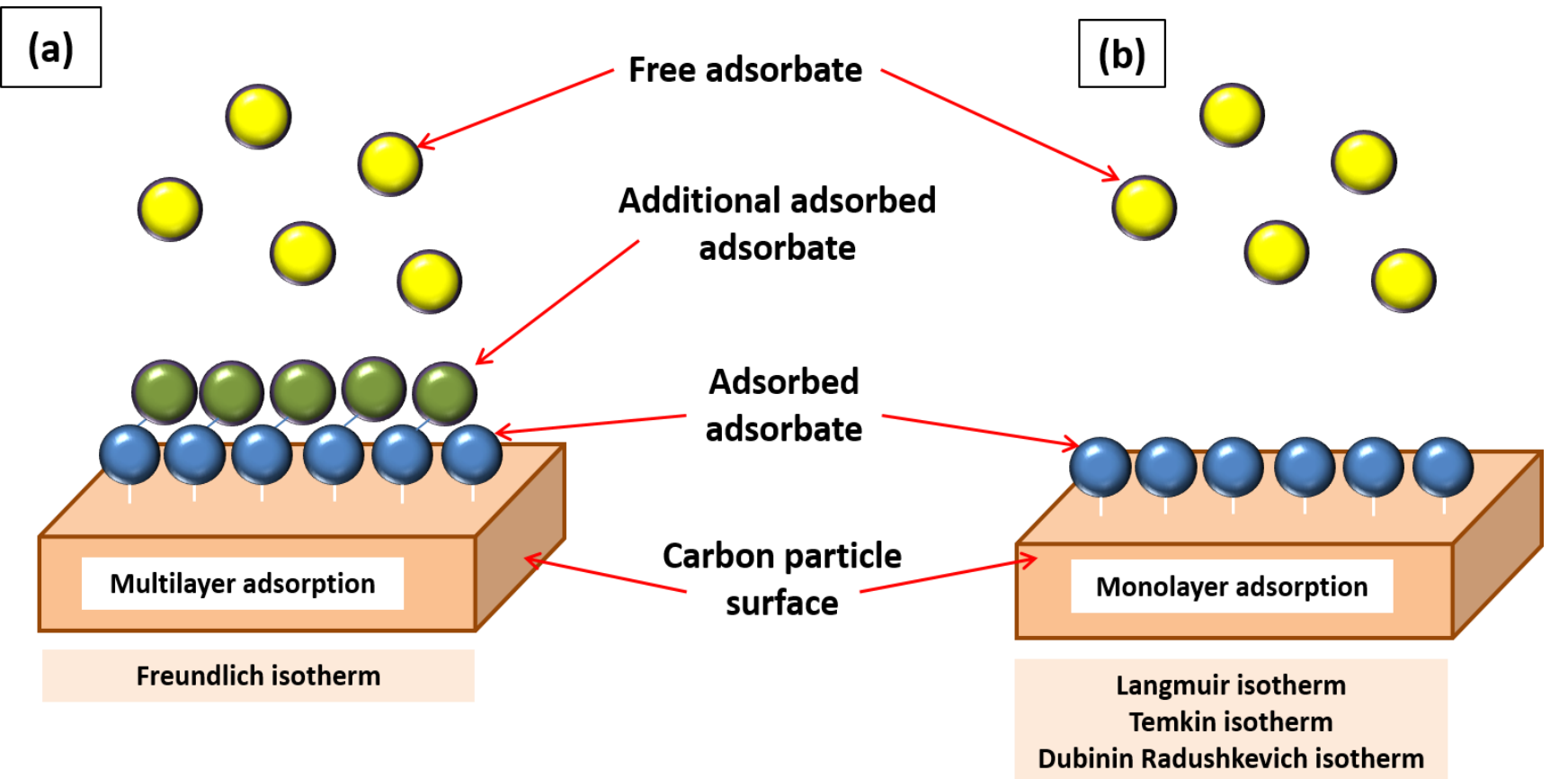

Fig. 1. Illustration of adsorption profile in multilayer (a) and monolayer (b) types.

(ii) $\quad R_{L}=1$ shows a linear adsorption process (the adsorption is independent in concentrations).

(iii) $\quad R_{L}=0$ is an irreversible adsorption process where the adsorbed adsorbate cannot diffuse or desorb. This commonly occurs in chemisorption.

(iv) $0<R_{L}<1$ is a favorable adsorption process, discouraging desorption process.

Temkin model describes a factor that explicitly refers to a condition in the adsorbent-adsorbate interactions. By disregarding the extremely low concentrations, the model replies the heat of adsorption of all molecules in a layer as the function of temperature [22], which is expressed as:

$$
q_{e}=\beta_{T}\left(\ln C_{e}\right)+\left(\beta_{T} \ln A_{T}\right)
$$

where $A_{T}$ is the equilibrium binding constant, and $\beta_{T}$ is the Temkin isotherm constant, informing [25]

(i) $\quad \beta_{T}<8 \mathrm{~kJ}$ implies physisorption.

(ii) $\quad \beta_{T}>8 \mathrm{~kJ}$ replies chemisorption.

Meanwhile, Dubinin-Radushkevich isotherm was applied for expressing the adsorption mechanism with a Gaussian energy distribution on a heterogeneous surface [26], which is expressed as:

$$
\begin{aligned}
& \ln q_{e}=\ln q_{s}-(\beta \varepsilon)^{2} \\
& \varepsilon=R T \ln \left[1+\frac{1}{C_{e}}\right] \\
& E=\frac{1}{\sqrt{2 \beta}}
\end{aligned}
$$

where $q_{s}, \beta$, and $\varepsilon$ represent the theoretical isoterm saturation capacity, the Dubinin-Radushkevich theoretical isotherm saturation capacity, and the Polanyi potential, respectively. $T$ is the absolute temperature $(\mathrm{K})$ and $R$ is the Boltzmann gas constant $(8.314 \mathrm{~J} / \mathrm{mol} \mathrm{K}) . E$ is the energy, describing [25]:

(i) $E<8 \mathrm{~kJ} / \mathrm{mol}$ is chemisorption.

(ii) $E>8 \mathrm{~kJ} / \mathrm{mol}$ is physisorption.

Adsorption efficiency was measured as:

$$
\% E=\left(\frac{C_{o}-C_{e}}{C_{o}}\right) \times 100 \%
$$

where $C_{o}$ and $\% \mathrm{E}$ are the initial concentration of adsorption $(\mathrm{mg} / \mathrm{L})$ and the adsorption efficiency $(\%)$, respectively.

The interactions between adsorbent surface and adsorbate molecules under physisorption and chemisorption as explained in the above models are illustrated in Figs. 2 (a) and (b), respectively.

\section{Materials and Methods}

Materials used in this study were pineapple peel (Ananas comosus; purchased from the local market in Subang, Indonesia) and curcumin (obtained by the extraction process of turmeric from local market in Bandung, Indonesia, using a similar method as reported in literature [18]).

In the experimental procedure, 200 grams of pineapple peel was cleaned, sliced, and carbonized for 1 hour at the temperature of $250^{\circ} \mathrm{C}$ in the ambient conditions, and ground using a saw-milling apparatus. To obtain the particle size distribution, carbon particles were put into a sieving apparatus (PT Rumah Publikasi Indonesia, Indonesia) with the hole sizes of 55, 74, 100, 125, 200, 500, 1000 , and $2000 \mu \mathrm{m}$. The prepared carbon particles were then cleaned from their impurities using a centrifugation (TG16WS High-Speed Benchtop Centrifuge, Zhengzhou 


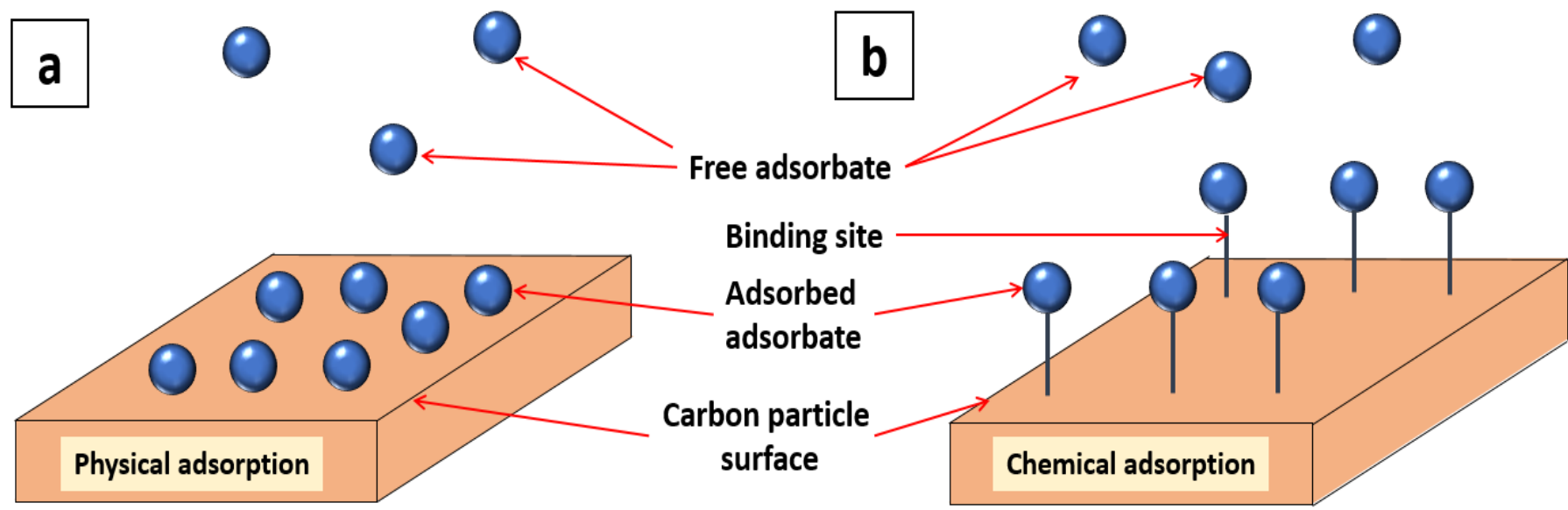

Fig. 2. Illustration adsorbent surface-adsorbent interaction mechanism in physisorption (a) and chemisorption (b) types.

Hepo International Trading, Co., Ltd., China; 11,000 rpm for 5 minutes) and dried in an electrical furnace at the temperature of $80^{\circ} \mathrm{C}$ to remove the physically adsorbed water.

To support the analysis, samples were characterized using a Fourier Transform Infrared (FTIR-4600, Jasco Corp., Japan) and a Digital Microscope (BXAW-AX-BC, China; 1000x magnification).

The adsorption test was done by adding the prepared carbon particles (0.05 grams) with a specific size to 100 $\mathrm{mL}$ of curcumin solution (with a specific concentration (i.e. 10, 30, and $50 \mathrm{ppm}$ ). Adsorption tests were carried out by mixing the curcumin-carbon solution at $1000 \mathrm{rpm}$ for 30 minutes in the ambient conditions and constant $\mathrm{pH}$ (about 7 ). For testing the adsorption at the specific time (every 10 minutes), the aliquot of solution was taken from the mixing solution, filtered using a nylon membrane syringe filter with the pore sizes of $0.22 \mu \mathrm{m}$, and analyzed using a Visible Spectroscope (Model 7205; JENWAY; ColeParner; US) analyzed at maximum wavelength in the range of 200 to $600 \mathrm{~nm}$. The adsorption results were plotted and normalized. Then, the maximum absorption peaks were calculated using the Beer's Law to obtain the concentration of curcumin. The obtained concentration data were plotted and compared to the standard isotherm adsorption models: Freundlich, Langmuir, Temkin, and Dubinin-Radushkevich models.

\section{Results}

Based on the observations using a Feret analysis in a digital microscope image (see Fig. 3(a)), carbon particles were found to have the sizes in the range of 45 to $2000 \mu \mathrm{m}$. Fig. 3 (b) presents the particle size distribution. Carbon particles mostly had some sizes between 100 and $500 \mu \mathrm{m}$ with a mean size of $248.09 \mu \mathrm{m}$. Here carbon particles with the sizes of $200 \mu \mathrm{m}$ were found as the highest percentage (reaching 50\%) compared to other sizes.

Figure 4 shows the FTIR analysis results of carbon particles from pineapple peel waste. The identical peaks and patterns of the carbon particles with different sizes were obtained, informing that the saw-milling method was effective to reduce particles without changing the chemical and elemental structure of the material [27].

The carbon particles consisted of several functional groups, including aliphatic group at 500-1253 $\mathrm{cm}^{-1}$ and hydroxyl groups $(\mathrm{O}-\mathrm{H})$ at 1600 and $3750 \mathrm{~cm}^{-1}$. There were two peaks in range of 1500 to $1750 \mathrm{~cm}^{-1}$, implying $\mathrm{C}-\mathrm{H}$ (out-of-plane bending). The appearance of absorption bands were found at 1650,3010 , and $3040 \mathrm{~cm}^{-1}$, corresponding to the unsaturated compound [28]. This FTIR analysis confirmed that the prepared particles were carbon material. Here, the carbon microparticles with various sizes can be used for further adsorption analyses. There will be no involvement of material crystallinity in the adsorption process, and all adsorption processes will be dependent upon the structure of carbon particles only.

The adsorption analysis was performed by linear fitting the results to the adsorption models. The linear fitting analyses are presented in Figs. 4 (a), (b), (c), and (d), corresponding to Freundlich, Langmuir, Temkin, and Dubinin-Radushkevich models, respectively. Table 1 presents the detailed parameters obtained based on the fitting analysis.

The best isotherm model based on $R^{2}$ value from the linear fitting analysis was found in the Freundlich isotherm model, closer to 1 . The data of Table 1 replied that the best fit isotherm models subsequently were Freundlich, Langmuir, Temkin, and Dubinin-Radushkevich. This table also discusses about the fitting analysis results for confirming what phenomena occurred during the adsorption process

\section{Discussion}

The digital microscope image (Fig. 3(a) and Fig. 3(b)) and the FTIR analysis results (Fig. 4) confirm the transformation of pineapple peel waste into carbon microparticles.

The adsorption analysis showed that the best isotherm model based on $R^{2}$ value from the linear fitting analysis was found in the Freundlich isotherm model, which was closer to 1 (see Table 1). The data of Table 1 replied that the best fit isotherm models subsequently were Freundlich, Langmuir, Temkin, and Dubinin-Radushkevich. The detailed explanations for each model are discussed as follows. 

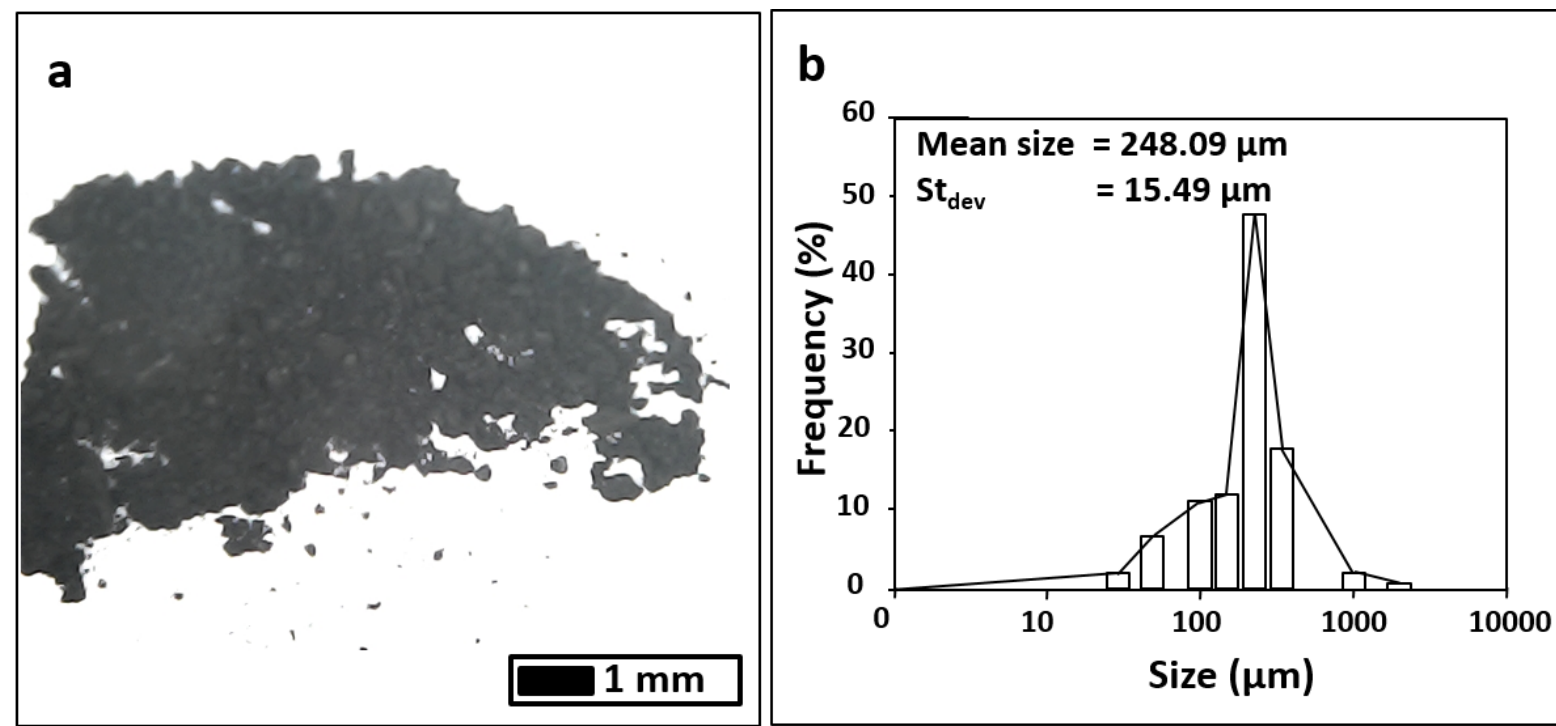

Fig. 3. Photograph image of carbon particles (a) and their particle size distribution (b).

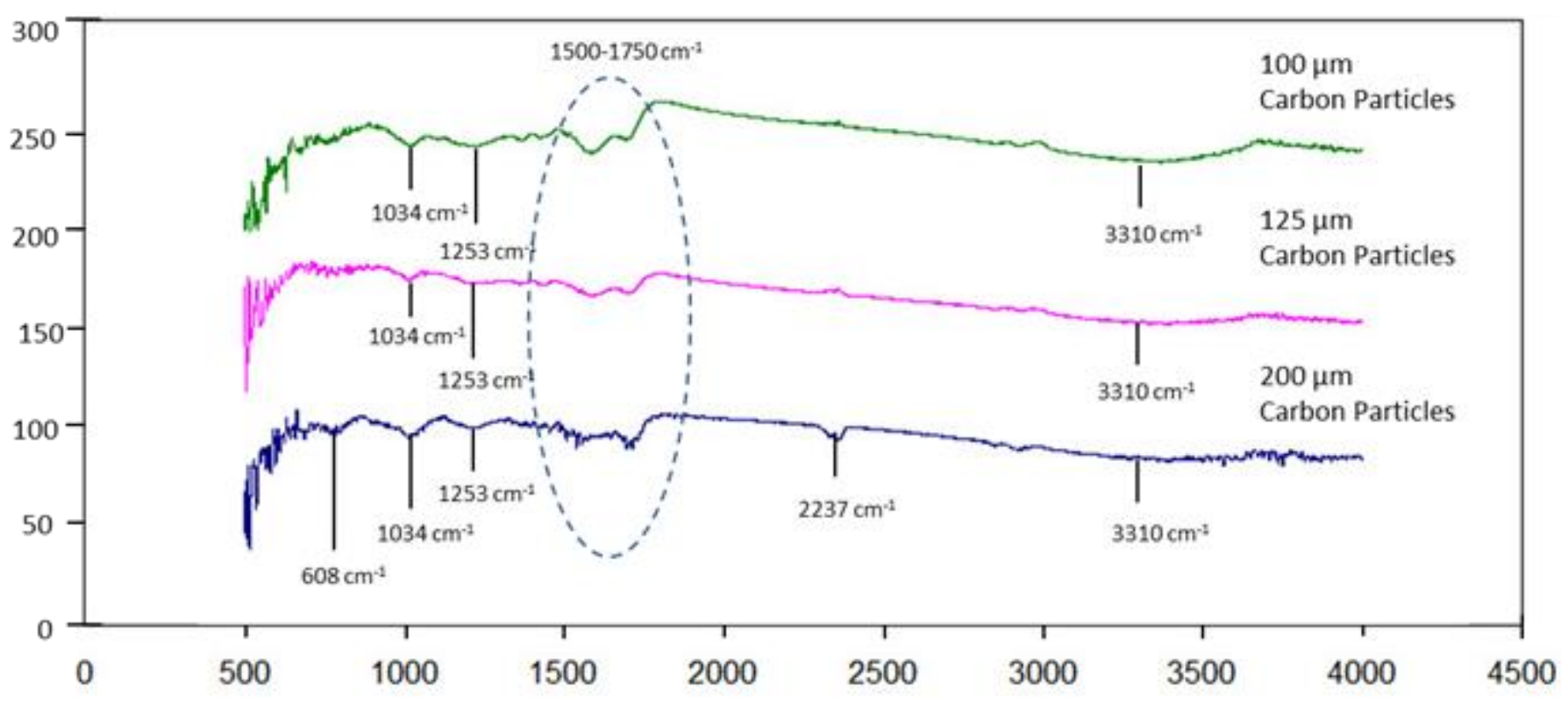

Fig. 4. FTIR analysis of carbon particles with different sizes from pineapple peel waste

The Freundlich isotherm model (see Fig. 5(a)) was the most appropriate model for explaining the type of adsorbing curcumin molecules on carbon microparticles compared to other models. The Freundlich parameters, including $k_{f}, n, 1 / n$, and $R^{2}$ values, were analyzed based on equation (1). From the experiments, the value of $1 / n$ followed $0.1<1 / n<0.5$, confirming that the adsorption occurred on heterogeneous surface of adsorbent. This also confirmed no cooperative adsorption during the process. Experiments found that the $k_{f}$ value was in the range of $0<$ $k_{f}<1$, implying favorable adsorption and discouraging desorption. The value of $1 / n$ less than 1 indicated a normal adsorption. The $n$ value obtained in this work was greater than 1 , informing the support of physical process in the adsorption.

The Langmuir isotherm adsorption model (see Fig. 5(b)) was found as the second best fit model in the fitting analysis. The Langmuir parameters, i.e. $q_{\max }, K_{L}, R_{L}$, and $R^{2}$ value, were investigated based on equations (2) and (3).
Unlike Freundlich model, the adsorption of Langmuir model has been assumed to be ideal and irreversible, giving restriction only to the formation of monolayer. Based on the experimental data, $R_{L}$ ranged between 0 and 1, implying the favorable adsorption, and this result was in a good line with the Freundlich model about favorability results.

The parameter of Temkin model (i.e., $A_{T}, \beta_{T}$, and $R^{2}$ ) (see Fig. 5(c)) was studied using equation (4). Temkin assumed that the heat adsorption of all molecules in the layer decreased linearly, which was characterized by the uniform distribution of binding energies. The regression value $R^{2}$ of Temkin model obtained in this work was less than Freundlich and Langmuir model. $\beta_{T}$ value indicated that $\beta_{T}<8 \mathrm{~kJ} / \mathrm{mol}$, indicating a physical adsorption (physisorption).

Linear fitting from Dubinin-Radushkevich model was analyzed for obtaining $q_{s}, E$, and $R^{2}$ values. The linear fitting analysis showed $E<8 \mathrm{~kJ} / \mathrm{mol}$, confirming that the type of adsorption of curcumin molecules onto carbon 

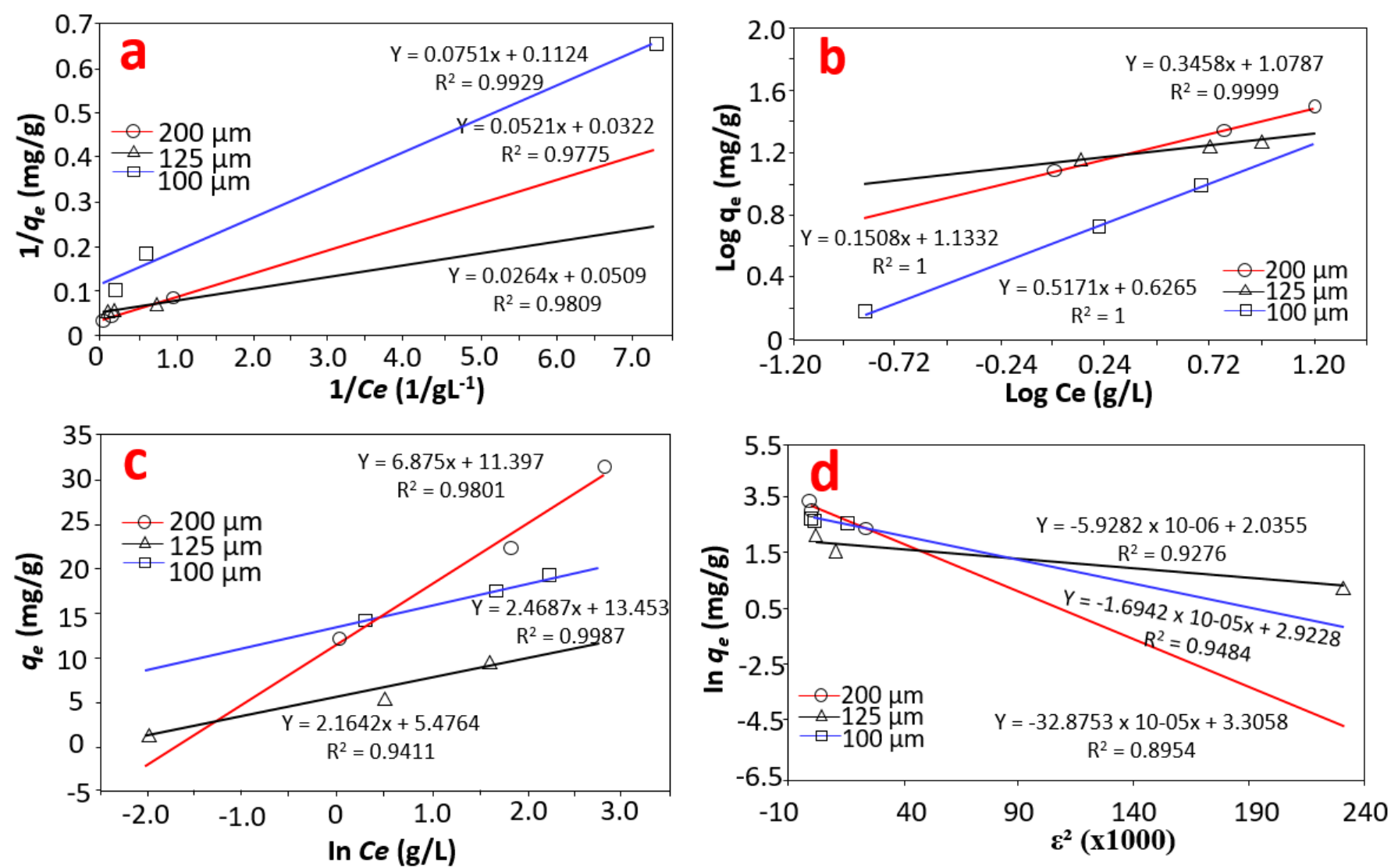

Fig. 5. Linear fitting of Freundlich (a), Langmuir (b), Temkin (c), and Dubinin-Radushkevich (d) adsorption isotherms models.

surface followed a physical process. Meanwhile, the Dubinin-Radushkevich model had the smallest regression value compared to Freundlich, Langmuir, and Temkin models. Therefore, Dubinin-Radushkevich model was the least appropriate model for this work.

The data of regression value in Table 1 indicated that the best fit isotherm models sequentially included Freundlich > Langmuir > Temkin > Dubinin-Radushkevich models. As explained above, since the best fit model related to Freundlich model, the type of adsorption of curcumin molecules onto the surface of carbon microparticle can be predicted as (i) Occurrence on the heterogeneous surface of adsorbent,

(ii) Interactions between adsorbed molecules,

(iii) Following multilayer adsorption.

The amount of adsorbed molecules refers to the total adsorption on all adsorption sites. The stronger binding sites occupy until the adsorption energy exponentially decreases upon the completion of the adsorption process. The heterogeneous surface is confirmed by $1 / n$ value. In this work, normal Freundlich adsorption also took place.

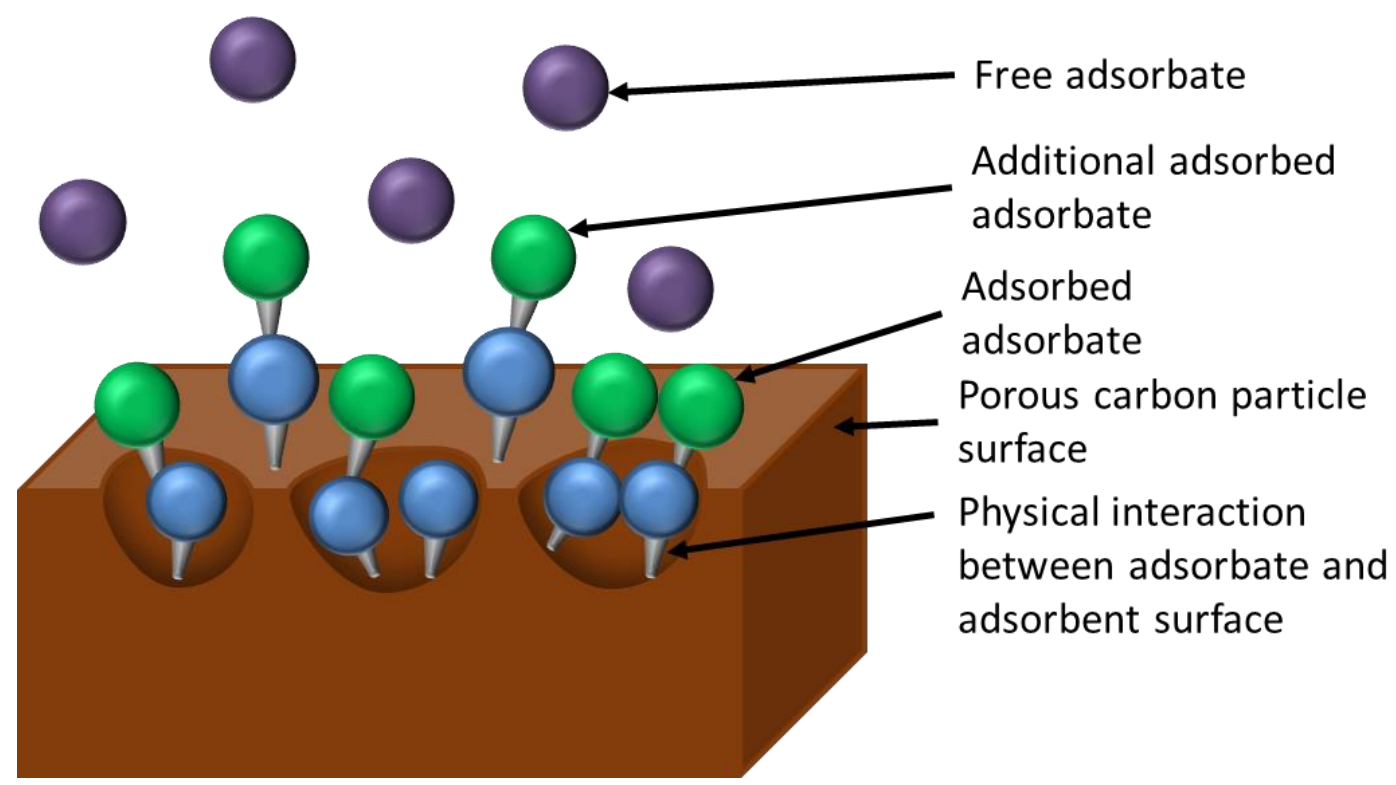

Fig. 6. Illustration of the adsorption profile in the porous adsorbent 
Table 1. Models of isotherm adsorption in this study

\begin{tabular}{|c|c|c|c|c|c|}
\hline \multirow{2}{*}{ Model } & \multirow{2}{*}{ Parameter } & \multicolumn{3}{|c|}{ Particle size $(\mu \mathrm{m})$} & \multirow[t]{2}{*}{ Notes } \\
\hline & & 100 & 125 & 200 & \\
\hline \multirow[t]{4}{*}{ Freundlich } & $n$ & 6.6313 & 1.9339 & 4.0683 & $\begin{array}{l}\text { above } 1 \text {, indicating } \\
\text { physisorption. }\end{array}$ \\
\hline & $1 / n$ & 0.1508 & 0.5171 & 0.2458 & $\begin{array}{c}0<1 / n<1 \text {, indicating } \\
\text { heteregenous surface, } \\
\text { favorable, and normal } \\
\text { adsorption. }\end{array}$ \\
\hline & $k_{f}(\mathrm{mg} / \mathrm{g})$ & 13.5894 & 4.2316 & 11.9867 & $\begin{array}{c}\text { The adsorption capacity of } \\
\text { the adsorbent. }\end{array}$ \\
\hline & $R^{2}$ & 1 & 1 & 0.999 & The correlation coefficient. \\
\hline \multirow[t]{5}{*}{ Langmuir } & $q_{\max }(\mathrm{mg} / \mathrm{g})$ & 19.646 & 8.897 & 31.056 & $\begin{array}{l}\text { The maximum adsorption } \\
\text { capacity of adsorbent. }\end{array}$ \\
\hline & $K_{L}(\mathrm{~L} / \mathrm{mg})$ & 1.9280 & 1.497 & 0.6180 & $\begin{array}{l}\text { Relatively small value, } \\
\text { indicating weak interaction } \\
\text { between adsorbate and } \\
\text { adsorbent. }\end{array}$ \\
\hline & $R_{L}$ & 0.0904 & 0.1193 & 0.0525 & $\begin{array}{l}0<\mathrm{R}_{\mathrm{L}}<1 \text {, indicating } \\
\text { favorable adsorption. }\end{array}$ \\
\hline & $\% E$ & 83.08 & 94.45 & 77.99 & $\begin{array}{l}\text { Relatively high percentage } \\
\text { of adsorption efficiency. }\end{array}$ \\
\hline & $R^{2}$ & 0.9809 & 0.9929 & 0.9775 & The correlation coefficient. \\
\hline \multirow[t]{3}{*}{ Temkin } & $A_{T}(\mathrm{~L} / \mathrm{g})$ & 1.1434 & 1.0490 & 1.3720 & $\begin{array}{l}\text { The equilibrium binding } \\
\text { constant. }\end{array}$ \\
\hline & $\beta_{T}(\mathrm{~J} / \mathrm{mol})$ & 100.3594 & 114.4798 & 36.0374 & $\begin{array}{c}\text { below } 8 \mathrm{~kJ} / \mathrm{mol} \text { indicating } \\
\text { physisorption. }\end{array}$ \\
\hline & $R^{2}$ & 0.9987 & 0.9411 & 0.9801 & The correlation coefficient. \\
\hline \multirow[t]{4}{*}{$\begin{array}{l}\text { Dubinin- } \\
\text { Radushkevich }\end{array}$} & $q_{s}(\mathrm{mg} / \mathrm{g})$ & 18.5933 & 17.6561 & 27.2703 & $\begin{array}{c}\text { Theoretical isotherm } \\
\text { capacity. }\end{array}$ \\
\hline & $\beta\left(\mathrm{mol}^{2} / \mathrm{kJ}^{2}\right)$ & $1.6942 \cdot 10^{-7}$ & $5.9282 \cdot 10^{-6}$ & $2.8753 .10^{-5}$ & $\begin{array}{l}\text { Dubinin-Radushkevich } \\
\text { isotherm constant. }\end{array}$ \\
\hline & $E(\mathrm{~kJ} / \mathrm{mol})$ & 1.7179 & 0.2904 & 0.1319 & $\begin{array}{c}\text { below } 8 \mathrm{~kJ} / \mathrm{mol} \text { indicating } \\
\text { physisorption. }\end{array}$ \\
\hline & $R^{2}$ & 0.9484 & 0.9276 & 0.8954 & The correlation coefficient. \\
\hline
\end{tabular}

Based on the Freundlich, Temkin, and DubininRadushkevich parameters, the adsorption of curcumin molecules onto carbon microparticles surface was a physical process. The adsorbate molecules were attracted to the adsorption site through the Van der Waals force, producing heat that was slightly greater than the sublimation of the adsorbates. This low heat of adsorption reduced the amount of energy required for desorption [29].

The existence of multilayer adsorption and no involvement of cooperative adsorption in the multilayer structure confirmed the interference of pore structure (see Figure 6). This is confirmed by the fact that pineapple peel

\section{Organic constituent Inorganic constituent}

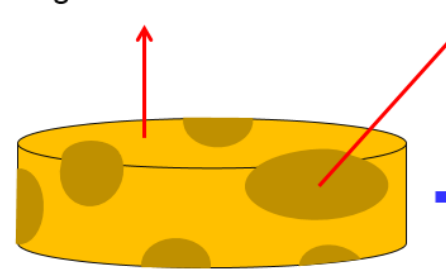

Pineapple peel waste

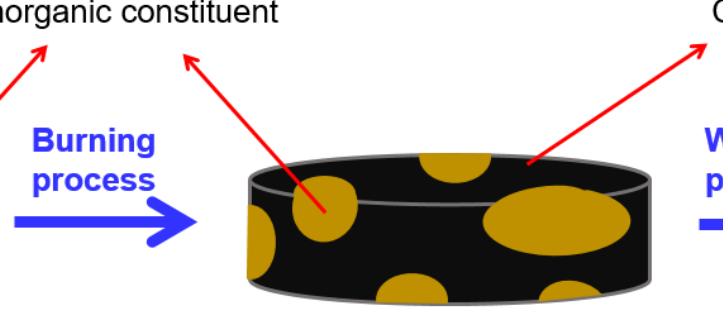

Composite (containing carbon and inorganic constituent)
Carbon Pores resulted from

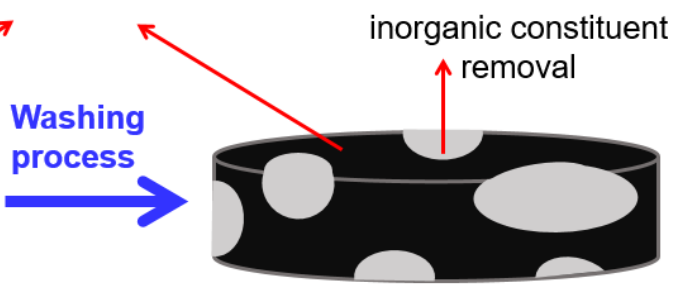

Carbon with pores

Fig. 7. Illustration of the pore formation in carbon particles 
waste contains some inorganic components (See Fig. 7). When pineapple peel waste is burned, the composite carbon/inorganic material is formed. Then, releasing inorganic components from the formed composite by washing method creates porous structures in the final product, in which this has been well-explained in our previous studies for the synthesis of porous carbon particles [9]. The existence of porous structure must indeed be confirmed by further analysis such as a nitrogen sorption analysis, which later on is done in our future work.

In addition, particle size has a major role in the adsorption. The adsorption efficiency of 100-, 125-, and $200-\mu \mathrm{m}$ carbon microparticles was 83.08, 94.45, and $77.99 \%$, respectively. Carbon microparticles with small sizes (i.e., 125 and $100 \mu \mathrm{m}$ ) have greater adsorption capability than that of large particles $(200 \mu \mathrm{m})$. This is because the smaller particle size has direct correlations to the promotion of larger surface area, providing a better adsorption ability [30].

Theoretically, as discussed above, small particles should have better adsorption efficiency than large ones. However, based on the experimental data, $100-\mu \mathrm{m}$ carbon particles were less efficient in the adsorption compared to $125-\mu \mathrm{m}$ carbon particles. The issues in the colliding and aggregating small particles become the main problems. Such inclination in the agglomeration forms larger particles [31], indeed resulting less surface area and giving consequences in the deterring adsorption ability (confirmed by $q_{\max }$ and $q_{s}$ values).

\section{Conclusion}

The adsorption characteristics of carbon microparticles

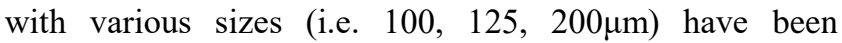
investigated for adsorbing curcumin molecules as a model of adsorbate. The adsorption results showed that the adsorption profiles of carbon microparticles in all sizes were appropriate to the Freundlich model, indicating multilayer adsorption on the heterogeneous surface. The adsorption followed a normal adsorption with a physical process, implying Van der Waals force in binding the adsorbate onto the surface of the carbon microparticles. The additional multilayer without cooperative adsorption confirmed the effect of surface structure (i.e. pores) on the adsorption. In addition, the adsorption profile of carbon microparticles with $125-\mu \mathrm{m}$ size was found as the most efficient. $100-\mu \mathrm{m}$ carbon particles, although they had larger surface area, had a lower adsorption ability due to the issues in the particle aggregation that could block the adsorption process into the deepest adsorption site in the adsorbent. This study is important for understanding what phenomena occur during the adsorption process and can be used for further uses, especially when using carbon from organic waste as a catalyst and an adsorbent.

\section{Acknowledgements}

This study acknowledged RISTEK BRIN for Grant-inaid Penelitian Terapan Unggulan Perguruan Tinggi
(PTUPT) and Bangdos Universitas Pendidikan Indonesia.

\section{References}

1. F. Yan, Z. Sun, H. Zhang, X. Sun, Y. Jiang and Z. Bai, The fluorescence mechanism of carbon dots, and methods for tuning their emission color: A review, Microchim. Acta 186 (2019) 546583.

2. L. A. T. Garcia, L. Boff, C. R. M. Barardi and M. Nagl, Inactivation of adenovirus in water by natural and synthetic compounds, Food Environ. Virol. 11 (2019) 157-166.

3. H. K. Sharma, C. Xu and W. Qin, Biological pretreatment of lignocellulosic biomass for biofuels and bioproducts: an overview, Waste Biomass Valori. 10 (2019) 235-251.

4. C. Bohringer, J. C. Carbone and T. F. Rutherford, Embodied carbon tariffs, Scandinavian J. Econ. 120 (2018) 183-210.

5. A. H. Jawad, A. M. Kadhum and Y. S. Ngoh, Applicability of dragon fruit (Hylocereus polyrhizus) peels as low-cost biosorbent for adsorption of methylene blue from aqueous solution: kinetics, equilibrium and thermodynamics studies, Desalin. Water Treat. 109 (2018) 231-240.

6. A. Bhatnagar, E. Kumar, A. K. Minocha, B. H. Jeon, H. Song,\& Seo, Y.C. Song, Removal of anionic dyes from water using Citrus limonum (lemon) peel: equilibrium studies and kinetic modeling, Sep. Sci. Technol. 44 (2009) 316-334.

7. B. H. Hameed, Removal of cationic dye from aqueous solution using jackfruit peel as non-conventional low-cost adsorbent, J. Hazard. Mater. 162 (2009) 344-350.

8. Z. Haddadian, M. A. Shavandi, Z. Z. Abidin, A. Fakhrul-razi and M. H. S. Ismail, Removal methyl orange from aqueous solutions using dragon fruit (Hylocereusundatus) foliage, Chem. Sci. Trans. 2 (2013) 900-910.

9. A. B. D. Nandiyanto, Z. A. Putra, R. Andika, M. R. Bilad, T. Kurniawan, R. Zulhijah and I. Hamidah, Porous activated carbon particles from rice straw waste and their adsorption properties, J. Eng. Sci. Technol. 12 (2017) 1-11.

10. A. Sukmafitri, R. Ragadhita, A. B. D. Nandiyanto, W. C. Nugraha, and B. Mulyanti, Effect of ph condition on the production of welldispersed carbon nanoparticles from rice husks, J. Eng. Sci. Technol. 15 (2020) 991-1000.

11. B. Wibowo, N. A. Masrurah, Y. U. Kasanah, F. Trapsilawati and M. A. Ilhami, Toward a taxonomy of micro and small manufacturing enterprises. Commun. Sci. Technol. 4 (2019) 74-80.

12. R. Ragadhita, A. B. D. Nandiyanto, W. C. Nugraha and A. Mudzakir, Adsorption isotherm of mesopore-free submicron silica particles from rice husk, J. Eng. Sci. Technol. 14 (2019) 2052-2062.

13. M. Fiandini, R. Ragadhita, A. B. D. Nandiyanto and W. C. Nugraha, Adsorption characteristics of submicron porous carbon particles prepared from rice husk, J. Eng. Sci. Technol. 15 (2020) 022-031.

14. B. Hub, K. Wang, L. Wu, S. H. Yu, M. Antonietti and M. M. Titirici, Engineering carbon materials from the hydrothermal carbonization process of biomass, Adv. Mater. 22 (2010) 813-828.

15. W. W. Ingwersen, Life cycle assessment of fresh pineapple from Costa Rica. J. Clean. Prod. 35 (2012) 152-163.

16. A. B. D. Nandiyanto, D. Sofiani, N. Permatasari, T. N. Sucahya, A. S. Wiryani, A. Purnamasari, and E. C. Prima, Photodecomposition profile of organic material during the partial solar eclipse of 9 march 2016 and its correlation with organic material concentration and photocatalyst amount. Indones. J. Sci. Technol. 1 (2016) 132- 
155

17. A. B. D. Nandiyanto, A.S. Wiryani, A. Rusli, A. Purnamasari, A.G. Abdullah, I. Widiaty and R. Hurriyati, Extraction of curcumin pigment from Indonesian local turmeric with its infrared spectra and thermal decomposition properties. IOP Conf. Series: Mater. Sci. Eng. 180 (2017) 012136.

18. A. B. D. Nandiyanto, S. G. Kim, F. Iskandar and K. Okuyama, Synthesis of spherical mesoporous silica nanoparticles with nanometer-size controllable pores and outer diameters, Micropor. Mesopor. Mat. 120 (2009) 447-453.

19. G. J. Romero, J. R. Peralta-Videa, E. Rodriguez, S. L. Ramirez and J. L. Gardea-Torresdey, Determination of thermodynamic parameters of $\mathrm{Cr}$ (VI) adsorption from aqueous solution onto Agave lechuguilla biomass, J. Chem. Thermodyn. 37 (2005) 343-347.

20. A. O. Dada, A. P. Olalekan, A. M. Olatunya and O. J. I. J. C. Dada, Langmuir, Freundlich, Temkin and Dubinin-Radushkevich isotherms studies of equilibrium sorption of $\mathrm{Zn2}+$ unto phosphoric acid modified rice husk, J. Appl. Chem. 3 (2012) 38-45.

21. I. A.W. Tan, A. L. Ahmad and B. H. Hameed, Adsorption of basic dye on high-surface-area activated carbon prepared from coconut husk: Equilibrium, kinetic and thermodynamic studies, J. Hazard. Mat. 154 (2008) 337-346.

22. I. Langmuir, The adsorption of gases on plane surfaces of glass, mica and platinum, J. Am. Chem. Soc. 40 (1918) 1361-1403.

23. E. Voudrias, K. Fytianos and E. Bozani, Sorption-desorption isotherms of dyes from aqueous solutions and wastewaters with different sorbent materials, Global NEST J. 4 (2002) 75-83.

24. H. K. Chung, W. H. Kim, J. Park, J. Cho, T.Y. Jeong and P.K. Park,
Application of Langmuir and Freundlich isotherms to predict adsorbate removal efficiency or required amount of adsorben, J. Ind. Eng. Chem. 28 (2015) 241-246.

25. N. Ayawei, A. N. Ebelegi and D. Wankasi, Modelling and interpretation of adsorption isotherms, J. Chem. 2017 (2017) 1-11.

26. A. Gunay, E. Arslankaya and I. Tosun, Lead removal from aqueous solution by natural and pretreated clinoptilolite: adsorption equilibrium and kinetics, J. Hazard. Mat. 146 (2007) 362-371.

27. A. B. D. Nandiyanto, R. Andika, M. Aziz and L.S. Riza, Working volume and milling time on the product size/morphology, product yield, and electricity consumption in the ball-milling process of organic material. Indones. J. Sci. Technol. 3 (2018) 82-94.

28. A. B. D. Nandiyanto, R. Oktiani and R. Ragadhita, How to read and interpret FTIR spectroscope of organic materia, Indones. J. Sci. Technol.. 4 (2019) 97-118.

29. A. H. Berger and A. S. Bhown, Comparing physisorption and chemisorption solid sorbents for use separating $\mathrm{CO}_{2}$ from flue gas using temperature swing adsorption, Energy Procedia. 4 (2011) 562567.

30. I. N. Najm, V.L. Snoeyink, M.T. Suidan, C. H. Lee and Y. Richard, Effect of particle size and background natural organics on the adsorption efficiency of PAC, J. Am. Water Works Ass. 82 ( 1990) $65-72$.

31. T. Tahara, Y. Imajyo, A. B. D. Nandiyanto, T. Ogi, T. Iwaki and K. Okuyama, Low-energy bead-milling dispersions of rod-type titania nanoparticles and their optical properties. Adv. Powder Technol, 25 (2014) 1492-1499. 